\title{
Altered fractionation short-course radiotherapy for stage II-III rectal cancer: a retrospective study
}

\author{
Hans Geinitz ${ }^{*}$ (D), Carsten Nieder ${ }^{2,3}$, Lukas Kocik', Christine Track', Johann Feichtinger ${ }^{1}$, Theresa Weingartner ${ }^{1}$, \\ Kurt Spiegl', Barbara Füreder-Kitzmüller ${ }^{1}$, Johanna Kaufmann', Dietmar H. Seewald ${ }^{4}$, Reinhold Függer ${ }^{5}$, \\ Andreas Shamiyeh ${ }^{6}$, Andreas L. Petzer ${ }^{7}$, David Kies/ ${ }^{8}$ and Josef Hammer ${ }^{1}$
}

\begin{abstract}
Purpose: To report the long-term outcomes of neoadjuvant altered fractionation short-course radiotherapy in 271 consecutive patients with stage II-III rectal cancer.

Patients and Methods: This was a retrospective single institution study with median follow-up of 101 months (8.4 years). Patients who were alive at the time of analysis in 2018 were contacted to obtain functional outcome data (phone interview). Radiotherapy consisted of $25 \mathrm{~Gy}$ in 10 fractions of $2.5 \mathrm{~Gy}$ administered twice daily. Median time interval to surgery was 5 days.
\end{abstract}

Results: Local relapse was observed in 12 patients (4.4\%) after a median of 28 months. Overall survival after 5 and 10 years was 73 and 55.5\%, respectively (corresponding disease-free survival 65.5 and 51\%). Of all patients without permanent stoma, $79 \%$ reported no low anterior resection syndrome (LARS; 0-20 points), 9\% reported LARS with 21-29 points and $12 \%$ serious LARS (30-42 points).

Conclusion: The present radiotherapy regimen was feasible and resulted in low rates of local relapse. Most patients reported good functional outcomes.

Keywords: Stage II-III rectal cancer, Neoadjuvant altered fractionation short-course radiotherapy, Low anterior resection syndrome (LARS)

\section{Introduction}

Pelvic radiotherapy is playing an important role in the treatment of rectal cancer and has, from a historical point of view, improved disease control already in the era that preceded effective resection strategies [1, 2]. Many randomized trials have proven that even with now standard total mesorectal excision (TME) surgery, preoperative radiotherapy [3] or chemoradiotherapy [4, 5] improve local control. Radiotherapy is mainly given in

\footnotetext{
* Correspondence: hans.geinitz@ordensklinikum.at

'Department of Radiation Oncology, Ordensklinikum Linz Barmherzige Schwestern, Seilerstätte 4, 4010 Linz, Austria

Full list of author information is available at the end of the article
}

cases where tumors are located in the distal and middle rectum, and preoperative schedules have proven to be more efficient and better tolerated than postoperative ones [4]. Locally advanced rectal cancer (LARC) is usually classified as T3, T4 or anterior distal T2, where the risk of local recurrence is significant with surgery alone. Despite increasing availability of prospective randomized studies, there is still room for differing treatment strategies, e.g. in different countries [6]. Commonly, centers preferring short-course neoadjuvant radiotherapy offer the classical 25 Gy in 5 fractions of 5 Gy regimen $[7,8]$. However, an Austrian group has introduced an altered fractionation variant $(25 \mathrm{~Gy}$ in 10 fractions of $2.5 \mathrm{~Gy}$

(c) The Author(s). 2020 Open Access This article is licensed under a Creative Commons Attribution 4.0 International License, which permits use, sharing, adaptation, distribution and reproduction in any medium or format, as long as you give appropriate credit to the original author(s) and the source, provide a link to the Creative Commons licence, and indicate if changes were made. The images or other third party material in this article are included in the article's Creative Commons licence, unless indicated otherwise in a credit line to the material. If material is not included in the article's Creative Commons licence and your intended use is not permitted by statutory regulation or exceeds the permitted use, you will need to obtain permission directly from the copyright holder. To view a copy of this licence, visit http://creativecommons.org/licenses/by/4.0/ The Creative Commons Public Domain Dedication waiver (http://creativecommons.org/publicdomain/zero/1.0/) applies to the data made available in this article, unless otherwise stated in a credit line to the data. 
administered twice daily) that was hypothesized to improve tolerability [9], in particular the development of lower anterior resection syndrome (LARS) [10]. The latter schedule has also been adopted in Linz, Austria, in 2002 and the purpose of the present study is to report the long-term outcomes in 271 consecutive patients.

\section{Patients and methods}

We performed a retrospective single institution cohort study with long-term follow-up. The study was approved by the local ethics committee. The inclusion period was 2002-2017. The median follow-up of the 271 patients was 101 months. Patients who were alive at the time of analysis in 2018 were contacted to obtain standardized functional outcome data (phone interview; Fig. 1). Date and patterns of relapse were abstracted from the hospital's patient records, with local relapse, disease-free survival and functional outcome (LARS) as co-primary endpoints. Overall survival was assessed, too. If no event of interest had occurred, patients were censored at the time of last documented contact with the hospital.

To outline the principles of multidisciplinary assessment and therapy, patients with histologically proven adenocarcinoma of the rectum without evidence of distant metastases were eligible for neoadjuvant short-course radiotherapy, if transmural extension was to be expected upon digital examination, rectoscopy, endosonography, pelvic computed tomography $(\mathrm{CT})$ and magnetic resonance imaging (MRI) scans. A complete resection of all visible disease extent, either by low anterior resection (LAR) with primary anastomosis or by abdominoperineal resection (APR), was expected feasible by the tumor board members. Selected patients not included in this study received long-term preoperative chemoradiotherapy with downsizing intent. All patients received flexible and rigid endoscopy, a CT of the abdomen and pelvis and a chest $\mathrm{x}$-ray for staging (in later years thorax CT). One hundred and fifty-five of $271 \mathrm{pa}-$ tients (56\%) additionally obtained an MRI of the pelvis. The percentage of patients staged with MRI increased over time: from $39 \%$ in the early years (2002-2006) to $82 \%$ at the end of the study period (2011-2017). High-risk features such as threatened radial margin or extramural vascular invasion (EMVI) were not regularly assessed.

The clinical target volume included the primary tumor, the mesorectal tissue including perirectal and presacral nodes, and internal iliac lymph nodes. The caudal boundary of the clinical target volume was at $5 \mathrm{~cm}$ caudal to the macroscopic tumor. Thus, the anus was included only in very low tumors. The perineum was not included in the target volume even if an APR was planned. Patients were treated in prone position (belly board) with comfortably full bladder, typically with conformal three field techniques, with a posterior and two lateral opposing wedged fields. Dose per fraction was 2.5 Gy calculated at the ICRU (International Commission on Radiation Units and Measurements) reference point. Two fractions with intervals between fractions of at least $6 \mathrm{~h}$ were delivered every day (25 Gy within 1 week). Surgery was planned within 1 week after radiotherapy (actual median 5 days, range 3-43 days). Depending on the location and extent of the carcinoma

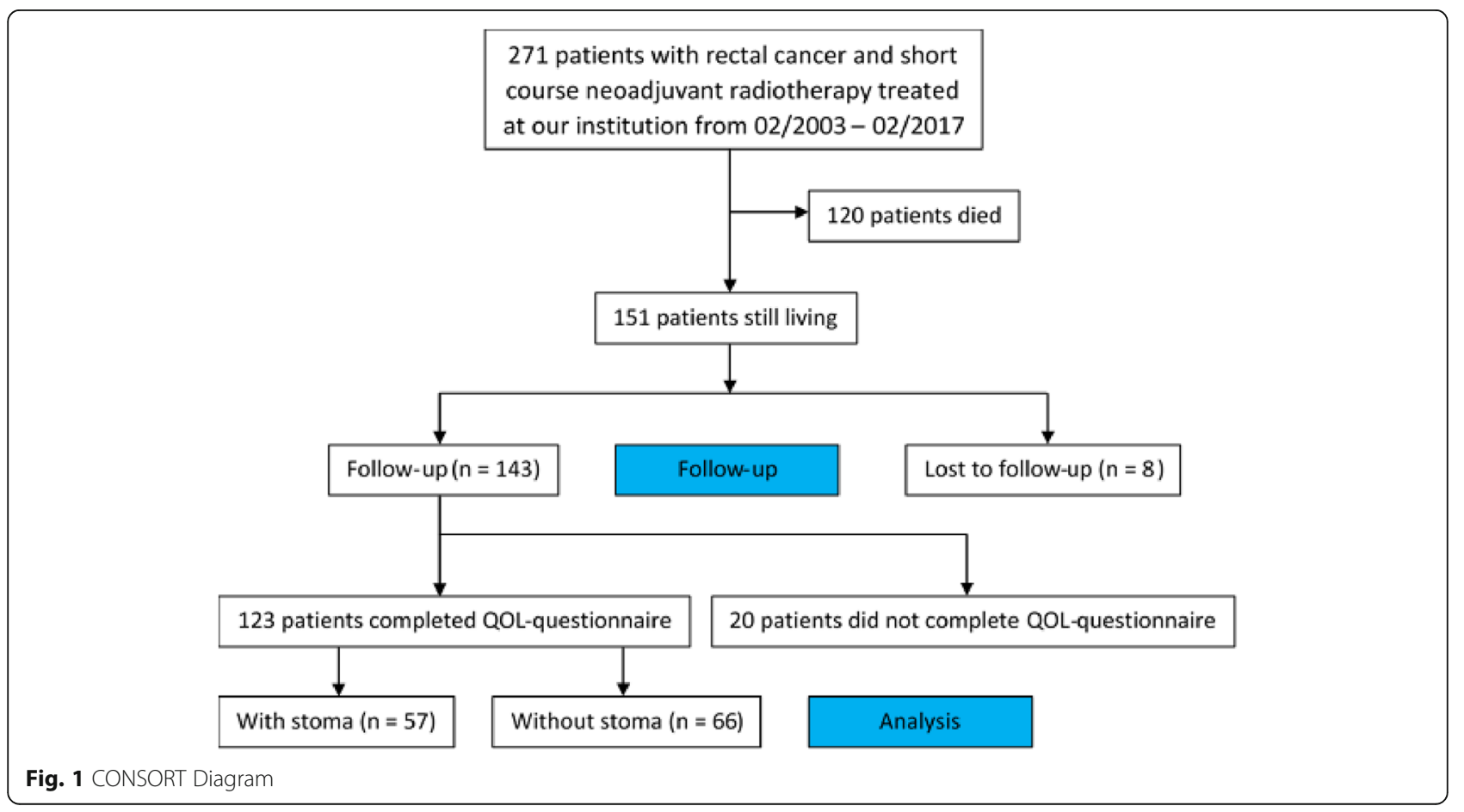


low anterior rectal resection or abdominoperineal amputation combined with TME were performed. None of the patients received neoadjuvant chemotherapy. Of all 271 patients, 164 received no adjuvant chemotherapy (61\%), 62 received adjuvant monotherapy (23\%, 5-FU or capecitabine) and 31 were treated with adjuvant polychemotherapy (11\%). No information on adjuvant chemotherapy was available for 14 patients (5\%).

Follow-up was every 3 months during the first year posttreatment, every 6 months during the second and third years, and yearly thereafter. Within the first 3 years, patients received an endoscopy (rectoscopy or recto-sigmoidoscopy) every 6 months and yearly afterwards. We scheduled a total colonoscopy after 1 year. During the first year, a biannual CT of the abdomen and pelvis was employed and yearly thereafter. During the first 8 years of the study period, we used an ultrasound of the liver at approximately every second follow up visit instead of an abdominal CT scan. At each visit, laboratory-tests were taken including carcinoembryonic antigen (CEA) and liver enzymes. During the first study years, patients received a yearly chest X-ray, after 2010 this was abandoned and substituted by a thorax CT in case of symptoms or a rising CEA.

Bowel function was assessed by telephone by directly inquiring the following standardized LARS items for patients without permanent stoma ([11]; Appendix 1): (1) Uncontrollable flatulences. (2) Accidental leakage of liquid stool. (3) Defecation frequency. (4) Repeated defecation within 1 hour. (5) Strong urgency to open the bowels. Patients with stoma answered the respective items from the EORTC QLQ CR 29 quality of life questionnaire ([12]; Appendix 2). Furthermore, the following symptoms were inquired and graded from 0 (no symptoms), 1 (mild symptoms), 2 (moderate symptoms) 3 (severe symptoms) and 4 (life threatening symptoms): Did you have obstipation? Did you have involuntary bowel movements? Did you have an elevated frequency in bowel movements or diarrhea? Did you have blood loss from the rectum? Did you have difficulties in urinating? Did you have involuntary loss of urine? Did you have increased urinary urgency? Did you observe a weak urinary stream? (Appendix 3).

\section{Statistics}

Survival was calculated by the Kaplan-Meier method using SPSS statistical software (IBM, Armonk, NY, USA). Of note, local recurrence was assessed by counting any local recurrence as event, regardless of whether this occurred as first recurrence or after metastasis.

\section{Results}

Most patients had male gender (65\%) and stage II disease $(65 \%)$, as shown in Table 1 . All patients completed radiotherapy. Acute side effects were limited to grade 1 . One hundred and thirty-seven patients (51\%) were treated with an abdominoperineal resection and 134 $(49 \%)$ with a low anterior resection (Table 1). Overall, 237 patients (87\%) had a stoma after surgery. In 107 patients (39\%) the stoma was temporary (median 179 days). Local relapse was observed in 12 patients (4.4\%) after a median of 28 months (range 8-92 months), Fig. 2. Overall survival after 5 and 10 years was 73.4 and $55.5 \%$, respectively (Fig. 3). Disease-free survival after 5 and 10 years was 65.5 and $51.2 \%$, respectively (Fig. 4). Distant metastases occurred in 44 patients $(16 \%)$ after a median interval of 29 months (range 1-92 months). Most metastases were recorded in the liver (21) or in multiple organs (15).

Out of 151 surviving patients, 123 (81\%) provided functional outcome data after a median of 114 months post-surgery (Fig. 1). In this subgroup, 66 patients had no stoma while 57 had a stoma. Of the patients without stoma $79 \%$ reported no LARS (0-20 points), while $9 \%$ reported LARS (21-29 points) and 12\% reported serious LARS (30-42 points). The most common individual symptom was fecal urge (65\% for all grades and frequencies combined), followed by increased defecation frequency ( $41 \%$ with $>1$ per $24 \mathrm{~h}$ ) and involuntary loss of liquid stools (39\% for all frequencies combined). Among patients with stoma, $11 \%$ reported leakage of stools from the stoma bag and $17 \%$ reported unintentional release of gas/flatulence. $12 \%$ noted sore skin around the stoma, $12 \%$ reported frequent bag changes during the day and 9\% during the night, $11 \%$ felt embarrassed about the stoma and $5 \%$ had problems in caring for the stoma.

Concerning urinary symptoms, 122 of 123 patients provided data and most patients reported no symptoms (grade 0) for the particular items (between 83 and 93\%). In detail, the following symptom grades were reported (percent grade $0,1,2,3,4$ ): difficulties in urinating 85,9 , 3,2 , and $0 \%$, respectively; involuntary loss of urine 83,3 , 10,2 , and $1 \%$, respectively; increased urinary urgency: $86,7,6,0$, and $1 \%$, respectively; weak urinary stream: 93 , $5,2,0$, and $0 \%$, respectively.

\section{Discussion}

This study employed phone-based longitudinal assessment of functional outcome (LARS) in long-term survivors of rectal cancer managed with a multimodal approach that included neoadjuvant short-course radiotherapy, mostly in male patients with tumors in the middle third of the rectum. Median follow-up was more than 8 years. A clear majority of surviving patients (81\%) provided functional outcome data. It is not possible to exclude that patients who did not provide data were dissatisfied with the outcomes and thus had more LARS symptoms and poorer quality of life than the majority of patients. Other drawbacks of the study include the following: retrospective design, lack of some baseline 
Table 1 Baseline characteristics

\begin{tabular}{|c|c|c|c|c|}
\hline & All patients & Available for functional outcome & $\begin{array}{l}\text { Available for functional } \\
\text { outcome without stoma }\end{array}$ & $\begin{array}{l}\text { Available for functional } \\
\text { outcome with stoma }\end{array}$ \\
\hline Number & 271 & 123 & 66 & 57 \\
\hline Age (median, range) in years & $70,37-94$ & $68,37-94$ & $65,37-94$ & $73,50-89$ \\
\hline Female gender & $95(35 \%)$ & 46 & $25(38 \%)$ & $21(37 \%)$ \\
\hline Male gender & $176(65 \%)$ & 77 & $41(62 \%)$ & $36(63 \%)$ \\
\hline Lower third tumor & $95(35 \%)$ & 42 & $10(15 \%)$ & $32(56 \%)$ \\
\hline Middle third & $149(55 \%)$ & 71 & $49(74 \%)$ & $22(39 \%)$ \\
\hline Upper third & $10(4 \%)$ & 3 & $2(3 \%)$ & $1(2 \%)$ \\
\hline Not documented & $17(6 \%)$ & 7 & $5(8 \%)$ & $2(4 \%)$ \\
\hline Follow-up (median, range) in months & $101,1-176$ & $104,13-178$ & $114,18-170$ & $91,13-176$ \\
\hline \multicolumn{5}{|l|}{ cTNM } \\
\hline сT2 & 15 & 6 & 4 & 2 \\
\hline cT3 & 243 & 115 & 62 & 53 \\
\hline cT4 & 8 & 1 & 0 & 1 \\
\hline unknown & 5 & 1 & 0 & 1 \\
\hline cNO & 97 & 52 & 24 & 28 \\
\hline $\mathrm{cN}+$ & 95 & 40 & 21 & 19 \\
\hline $\mathrm{cNx}$ & 79 & 31 & 21 & 10 \\
\hline \multicolumn{5}{|l|}{ pTNM } \\
\hline pT1 & 16 & 7 & 3 & 4 \\
\hline pT2 & 87 & 48 & 27 & 21 \\
\hline pT3 & 154 & 60 & 33 & 27 \\
\hline pT4 & 12 & 7 & 3 & 4 \\
\hline pTx & 2 & 1 & 0 & 1 \\
\hline pNO & 155 & 81 & 41 & 40 \\
\hline pN1 & 77 & 31 & 20 & 11 \\
\hline pN2 & 37 & 10 & 4 & 6 \\
\hline $\mathrm{pNx}$ & 2 & 1 & 1 & 0 \\
\hline \multicolumn{5}{|l|}{ MRI preoperatively } \\
\hline 0 & 116 & 43 & 24 & 19 \\
\hline 1 & 155 & 80 & 42 & 38 \\
\hline Abdominoperineal resection & 137 & 37 & 0 & 37 \\
\hline Low anterior resection & 134 & 86 & 66 & 20 \\
\hline
\end{tabular}

information that might interfere with function (comorbidity etc.), lack of information about surgical complications and several different late complications (second primary cancers, impaired sexuality etc.) and management of metastatic disease. Despite these drawbacks the present data provide interesting insights, and allow for discussion of a radiobiologically intriguing variant of the commonly employed 25 Gy short-course regimen.

Splitting the daily dose into two equally sized fractions of $2.5 \mathrm{~Gy}$ and adhering to a sufficiently long time interval of at least $6 \mathrm{~h}$ allows for reduction of late side effects such as fibrosis (reduced biologically equivalent dose for late responding normal tissues) [13], thereby reducing rectal injury [14]. The target volume and treatment planning concepts used in our study were in line with general principles $[15,16]$ and also included positioning on a belly board, which limits the amount of irradiated small bowel. Widder et al. used the same regimen in a smaller study $(n=184)$ with largely comparable, favorable results [9]. Their actuarial 4-year-local-recurrence rate was 2\%. Disease-free survival at 4 years was $69 \%$ (65\% at 5 years in our study). Postoperative mortality was $0.5 \%$ (one patient), early anastomotic leakage occurred in $11 \%$, and anastomotic stenosis requiring treatment in 


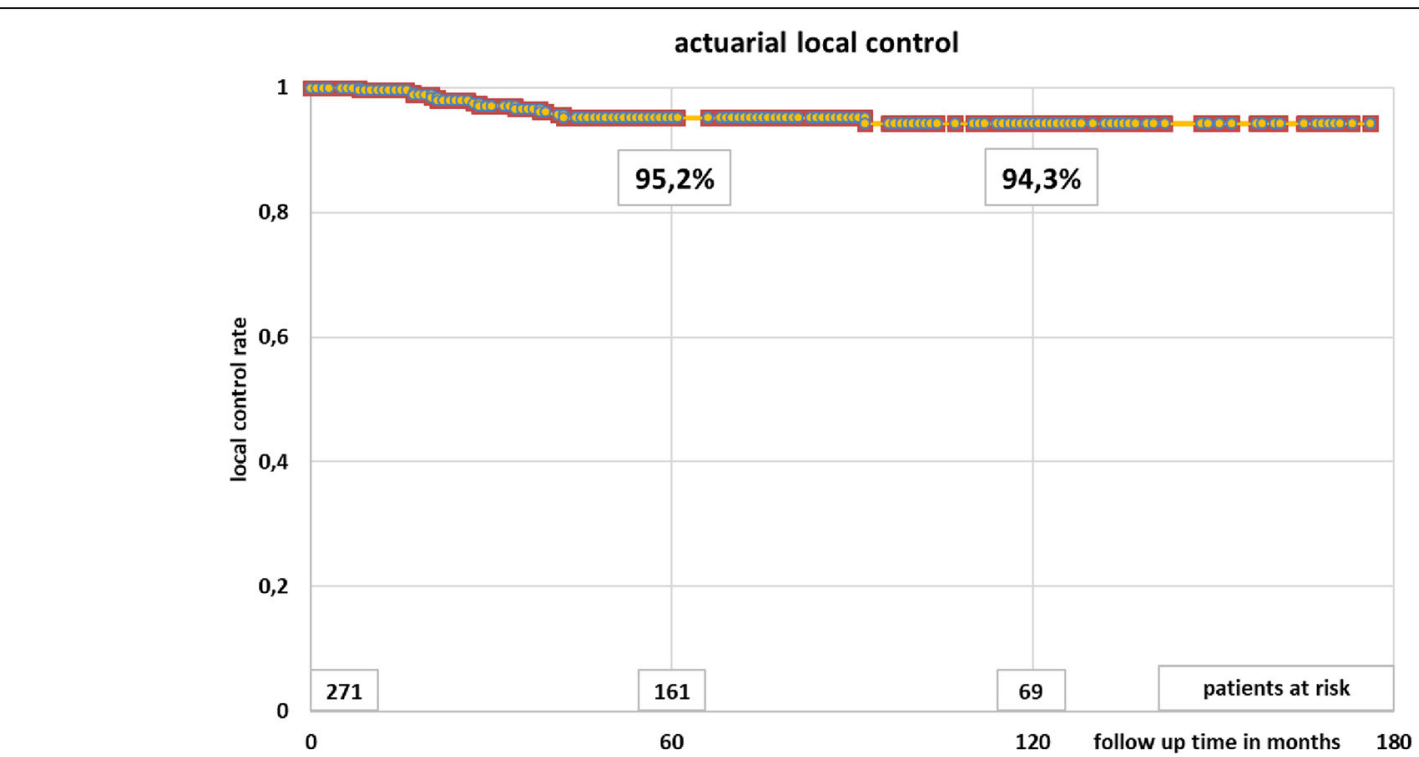

Fig. 2 Actuarial local control after neoadjuvant short-course radiotherapy and surgery

$6 \%$, of 132 patients with primary anastomosis. Randomized head to head comparisons of the 5- and 10-fraction regimen are not available. A disadvantage of the 10-fraction regimen is the fact that it is more time consuming for both patients and radiation oncology departments.

Different groups have reported results after standard $5 \times 5$ Gy neoadjuvant therapy. In the TME trial (19961999), 1530 Dutch patients with rectal cancer were randomized to TME preceded by $5 \times 5$ Gy or TME alone [17]. A set of questionnaires was sent to the surviving patients $(n=583)$ in 2012 . The questionnaires included LARS score, EORTC QLQ-C30 and EORTC QLQ-CR29 quality of life questionnaires. The LARS score range was divided into no LARS, minor LARS, and serious LARS categories. Of the 478 respondents, 242 non-stoma patients were included in the analysis. The median interval since treatment was 14.6 years. Serious LARS was reported by $46 \%$ of all patients (56\% after radiotherapy plus TME vs. $35 \%$ after TME). These figures were higher than those reported in our study population (shorter follow-up). Dutch patients with serious LARS fared worse in many quality of life domains.

The Trans-Tasman Radiation Oncology Group trial TROG 01.04 compared acute adverse events (AE) and postoperative complication rates in a randomized trial of short-course versus long-course preoperative radiotherapy

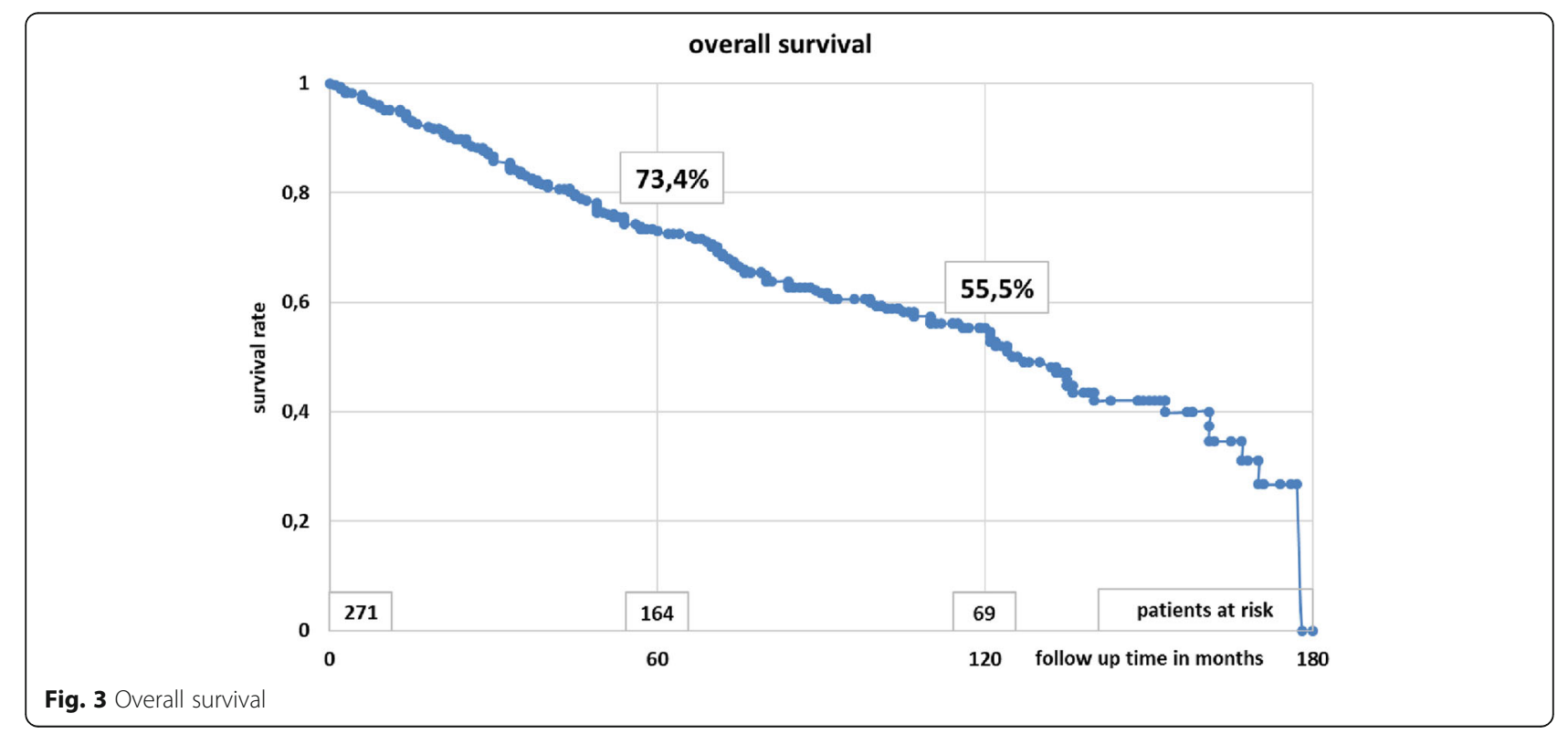




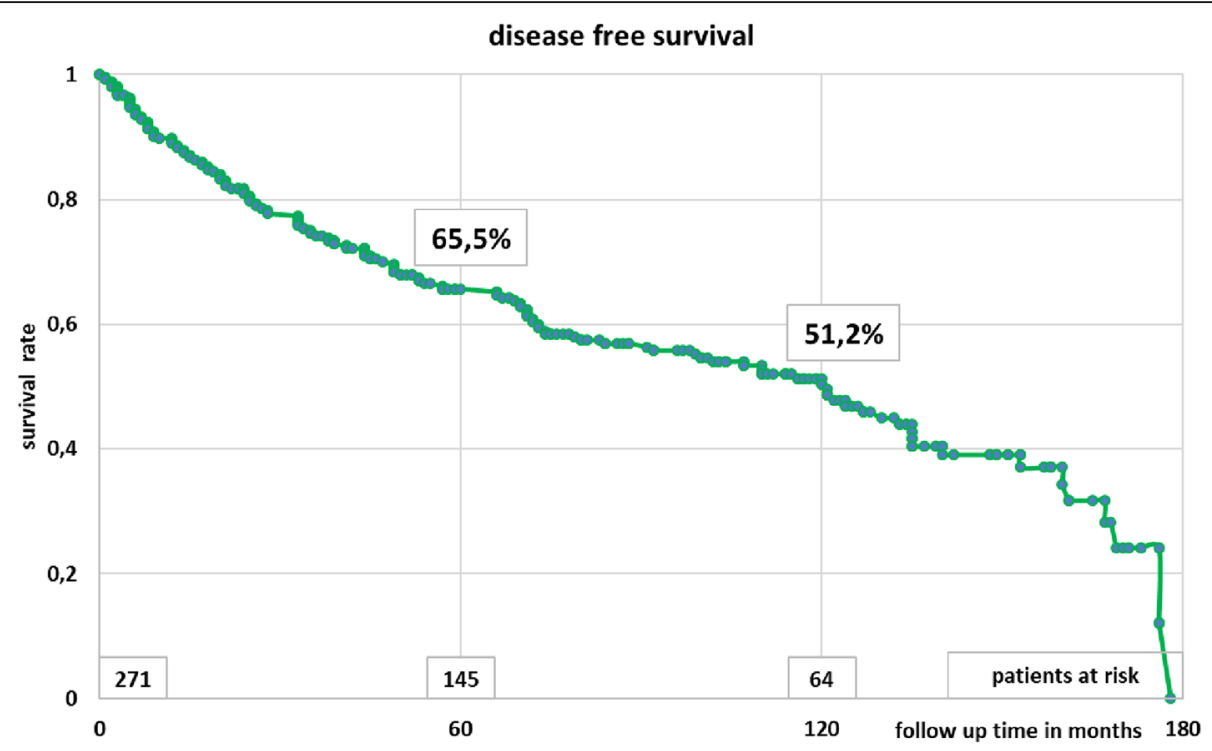

Fig. 4 Disease-free survival

[18]. Eligible patients had T3 rectal adenocarcinoma within $12 \mathrm{~cm}$ of the anal verge with no evidence of metastasis. Long-course therapy was 50.4 Gy administered in 28 fractions during 5.5 weeks, with infusion 5 -fluorouracil, and surgery in 4 to 6 weeks. There was no 30-day operative mortality. A statistically significant higher percentage of at least one $\mathrm{AE}$ occurred in the long-course group (72\% vs. 99\%; $p<0.001)$. There were significant differences in favor of short-course therapy for grade $3 \mathrm{AE}$ : radiation dermatitis $(0 \%$ vs. $6 \%, p=0.003)$, proctitis ( $0 \%$ vs. $4 \% ; p=$ $0.016)$, nausea ( $0 \%$ vs. $3 \% ; p=0.029)$, fatigue ( $0 \%$ vs. $4 \%$; $\mathrm{p}=0.016)$ and grade $3 / 4$ diarrhea rates $(1 \%$ vs $14 \% ; \mathrm{p}<$ $0.001)$. No statistically significant differences in surgical complication rates were seen $(53 \%$ vs. $50 \% ; p=0.68)$, although permanent stoma (38\% vs. $30 \% ; p=0.13)$ and anastomotic breakdown ( $7 \%$ vs. $3.5 \% ; p=0.26)$ rates favored long-course, with perineal wound complications ( $38 \%$ vs. $50 \% ; \mathrm{p}=0.26)$ in favor of short-course. Longterm outcomes were not reported in this publication.

Outcomes from Poland were based on a randomized phase 2 trial [19]. Patients $(n=515)$ with cT4 or fixed CT3 rectal cancer were randomized either to preoperative $5 \times 5$ Gy and three cycles of FOLFOX4 or to chemoradiation $(50.4 \mathrm{~Gy}$ with bolus 5-FU, leucovorin and oxaliplatin). The median follow-up was 7.0 years. There was no difference in disease-free survival, hazard ratio 0.95 (95\% confidence interval $0.75-1.19$ ), at 8 years $43 \%$ vs. $41 \%$ in the short-course vs. long-course group, respectively. The rate of late complications was similar ( $p=0.66$ ), grade $3+$ being $11 \%$ vs. $9 \%$ in the short-course vs. long-course group, respectively.
Stockholm III was a randomized phase 3 noninferiority trial where patients with a biopsy-proven adenocarcinoma of the rectum, without signs of nonresectability or distant metastases, and planned for an abdominal resection were eligible [20]. Participants were randomly assigned to receive either $5 \times 5$ Gy with surgery within 1 week or after 4-8 weeks (short-course radiotherapy with delay) or 25 fractions of 2 Gy with surgery after 4-8 weeks (long-course radiotherapy with delay). The primary endpoint was time to local recurrence. In patients with any local recurrence, median time from date of randomization to local recurrence in the pooled short-course radiotherapy comparison was 33 months (range 18-62 moths). Cumulative incidence of local recurrence in the whole trial was eight of 357 patients who received short-course radiotherapy, ten of 355 who received short-course radiotherapy with delay, and seven of 128 who received long-course radiotherapy (deemed non-inferior). Acute radiation-induced toxicity was recorded in one patient $(<1 \%)$ of 357 after shortcourse radiotherapy, 23 (7\%) of 355 after short-course radiotherapy with delay, and six (5\%) of 128 patients after long-course radiotherapy with delay. Frequency of postoperative complications was similar between all arms. However, in a pooled analysis of the two shortcourse radiotherapy regimens, the risk of postoperative complications was significantly lower after short-course radiotherapy with delay than after short-course radiotherapy (144 (53\%) of 355 vs. 188 (41\%) of 357; $p=$ $0.001)$. Based on their findings, the authors suggested that short-course radiotherapy with delay to surgery is a 
useful alternative to conventional short-course radiotherapy with immediate surgery.

A Dutch study $(n=156)$ compared quality of life between short and long-course therapy from diagnosis until 24 months after treatment [21]. The patients had clinical stage T2-3 N0-2 M0 and were treated between 2013 and 2017. The EORTC-C30 and EORTC QLQCR29 quality of life questionnaires were employed before the start of neoadjuvant treatment (baseline) and at $3,6,12,18$ and 24 months after. The long-course group reported poorer emotional functioning at 3, 6, 12, 18 and 24 months (mean difference with short course: - 9.4, $-12.1,-7.3,-8.0$ and -7.9 , respectively), and poorer global health, physical-, role-, social- and cognitive functioning at 6 months. Besides emotional functioning, all domains were comparable at 12,18 and 24 months. Within-group changes showed a significant improvement of emotional functioning after baseline in the short-course group. Thus, long-course therapy may induce a stronger decline in short-term quality of life than short-course treatment.

In a different study, all individuals 12 to 36 months after receiving a diagnosis of colorectal cancer in England were sent a survey in January 2013 [22]. The survey responses were linked with cancer registration, hospital admissions, and radiation therapy data. Outcome measures were cancer specific (Functional Assessment of Cancer Therapy and Social Difficulties Inventory items related to fecal incontinence, urinary incontinence, and sexual difficulties) and generic (EuroQol EQ-5D questionnaire). Surveys were returned by $6713(64 \%)$ of 10 , 452 patients with rectal cancer. Of these, 3998 patients were in remission after a major resection and formed the final analysis sample. Compared with those who had surgery alone, patients who received preoperative radiation therapy had higher odds of reporting poor bowel control $(44 \%$ vs. $33 \%$; odds ratio $(\mathrm{OR})=1.55$; $95 \%$ confidence interval, range 1.26-1.91), severe urinary leakage ( $7 \%$ vs. $3.5 \%$; OR $=1.69 ; 95 \%$ confidence interval, range $1.18-2.43)$, and severe sexual difficulties (34\% vs. $18 \%$; $\mathrm{OR}=1.73 ; 95 \%$ confidence interval, range 1.43-2.11). Patients who received long-course chemoradiation reported significantly better bowel control than those who had short-course radiation therapy, with no difference for other outcomes. Respondents with a stoma present reported significantly higher levels of severe sexual difficulties and worse health-related quality of life than those who had never had a stoma or had undergone stoma reversal.

Overall, these studies suggest that strategies attempting toxicity reduction and quality of life improvements still are warranted, including gentle ways of radiotherapy delivery. Other current developments include use of MRI-guided radiotherapy [23], selected chemoradiation, just in cases with margin threatening tumors [24, 25], total neoadjuvant therapy [26, 27], local excision or watch and wait approaches [28], and attention towards lateral local recurrence in low rectal cancer after neoadjuvant therapy [29], e.g. in cases with persistently enlarged nodes in the internal iliac compartment.

If the results of this study with regard to local tumour control could be transferred to a more selected group of high-risk patients (deep invasion beyond the muscularis propria, threatened margin, or EMVI) remains to be determined. In any case one would expect more local failures in such a study population. However, if $10 \times 2.5 \mathrm{~Gy}$ in five days or the commonly used short course regimen with $5 \times 5$ Gy or long course radio-chemotherapy would be more effective in such a high-risk population needs further (prospective) data from series with quality assured preoperative MRI-based selection criteria.

Concerning the choice of pre-operative radiotherapy in the presence of high-risk features, we proceed analogue to the ESMO guideline recommendation, e.g neoadjuvant short course radiotherapy or long course radio-chemotherapy for "bad" tumours, and long course radio-chemotherapy for "advanced/ugly" tumours or in case tumour shrinkage is needed [30]. For the short course radiotherapy regimen, our institution applies $10 \times 2.5$ Gy instead of $5 \times 5$ Gy.

\section{Conclusion}

The present radiotherapy regimen was feasible and resulted in low rates of local relapse. Most patients reported good functional outcomes, compared for example to the older Dutch TME trial [17].

\section{Supplementary information}

Supplementary information accompanies this paper at https://doi.org/10. 1186/s13014-020-01566-8.

Additional file 1. LARS-Score [11]

Additional file 2. Questionnaire for patients with permanent stoma (based on EORTC QLQ-CR29)

Additional file 3. Bowel and urinary symptom questionnaire (based on (TCAE)

\section{Abbreviations}

AE: Adverse Events; APR: Abdominoperineal Resection; CT: Computed Tomography; CEA: Carcino-Embryonic Antigen; EMVI: Extramural Vascular Invasion; EORTC: European Organisation for Research and Treatment of Cancer; EORTC QLQ-CR29: EORTC Quality of Life Questionnaire (Colorectal Module containing 29 questions); EORTC QLQ-C30: Generic EORTC Quality of Life Questionnaire for Cancer containing 30 questions; EuroQol EQ-5D: A Measure of Health Status from the EuroQol Group; ICRU: International Commission on Radiation Units and Measurements; LAR: Low Anterior Resection; LARC: Locally Advanced Rectal Cancer; LARS: Low Anterior Resection Syndrome; MRI: Magnetic Resonance Imaging; OR: Odds Ratio; TME: Total Mesorectal Excision 


\section{Authors' contributions}

HG made substantial contributions to the conception of the work. HG made substantial contributions to the design of the work. HG, LK, JF, TW, KS, DHS, AS, ALP, DK and JH made substantial contributions to the acquisition and analysis of data. HG, LK, CT and JF made substantial contributions to the interpretation of data. $\mathrm{HG}, \mathrm{CN}, \mathrm{JK}, \mathrm{BFK}$ and RF have drafted the work or substantively revised it. All authors read and approved the final manuscript.

\section{Funding}

This research did not receive any specific grant from funding agencies in the public, commercial, or not-for-profit sectors.

\section{Availability of data and materials}

The raw datasets used and analysed during the current study are not publicly available due to data privacy acts, but further general information about the project is available from the corresponding author on reasonable request.

\section{Ethics approval and consent to participate}

This non-inventional trial was approved by the local ethics committee under the direction of Prim.-Doz. Dr. Oleksiy Tsybrovskyy on Sept. 13th, 2018, using the (house-internal) number EKS 21/18

\section{Consent for publication}

Because there are no details on individuals reported within this manuscript, consent for publication of images is not required.

\section{Competing interests}

The authors declare that they have no competing interests, neither financial nor non-financial.

\section{Author details}

'Department of Radiation Oncology, Ordensklinikum Linz Barmherzige Schwestern, Seilerstätte 4, 4010 Linz, Austria. ${ }^{2}$ Department of Oncology and Palliative Medicine, Nordland Hospital, Bodø, Norway. ${ }^{3}$ Department of Clinical Medicine, UiT - The Arctic University of Norway, Troms $\varnothing$, Norway. ${ }^{4}$ Department of Radiotherapy, Oberoesterreichische Gesundheitsholding GmbH, Salzkammergut Klinikum Vöcklabruck, Vöcklabruck, Austria. ${ }^{5}$ Deptartment of Surgery, Ordensklinikum Linz Barmherzige Schwestern Elisabethinen, Linz, Austria. 'Department of Surgery, Kepler Universitaetsklinikum, Linz, Austria. ${ }^{7}$ Department of Internal Medicine I for Hematology with Stem Cell Transplantation, Hemostaseology and Medical Oncology, Ordensklinikum Linz Barmherzige Schwestern - Elisabethinen, Linz, Austria. ${ }^{8}$ Department of Internal Medicine - Hematology and Oncology, Kepler Universitaetsklinikum, Linz, Austria.

Received: 30 January 2020 Accepted: 8 May 2020

Published online: 14 May 2020

\section{References}

1. Willett CG, Czito BG, Bendell JC. Radiation therapy in stage II and III rectal cancer. Clin Cancer Res. 2007;13:6903s-8s.

2. Ceelen WP, Van Nieuwenhove Y, Fierens K. Preoperative chemoradiation versus radiation alone for stage $\|$ and III resectable rectal cancer. Cochrane Database Syst Rev. 2009;CD006041.

3. Kapiteijn E, Marijnen CA, Nagtegaal ID, et al. Preoperative radiotherapy combined with total mesorectal excision for resectable rectal cancer. N Engl J Med. 2001;345:638-46.

4. Sauer $\mathrm{R}$, Liersch $\mathrm{T}$, Merkel $\mathrm{S}$, et al. Preoperative versus postoperative chemoradiotherapy for locally advanced rectal cancer: results of the German CAO/ARO/AIO-94 randomized phase III trial after a median followup of 11 years. J Clin Oncol. 2012;30:1926-33.

5. Gérard JP, Azria D, Gourgou-Bourgade S, et al. Clinical outcome of the ACCORD 12/0405 PRODIGE 2 randomized trial in rectal cancer. J Clin Oncol. 2012;30:4558-65

6. Glimelius B, Myklebust TA, Lundqvist K, Wibe A, Guren MG. Two countries two treatment strategies for rectal cancer. Radiother Oncol. 2016;121:35763.

7. Graf W, Dahlberg M, Osman MM, Holmberg L, Pählman L, Glimelius B. Short-term preoperative radiotherapy results in down-staging of rectal cancer: a study of 1316 patients. Radiother Oncol. 1997;43:133-7.
8. Jensen LH, Altaf R, Harling H, Jensen M, Laurberg S, Lindegaard JC, Muhic A, Vestermark L, Jakobsen A, Bülow S. Danish Colorectal Cancer Group. Clinical outcome in 520 consecutive Danish rectal cancer patients treated with short course preoperative radiotherapy. Eur J Surg Oncol. 2010;36:237-43.

9. Widder J, Herbst F, Dobrowsky W, Schmid R, Pokrajac B, Jech B, Chiari C, Stift A, Maier A, Karner-Hanusch J, Teleky B, Wrba F, Jakesz R, Poetter R. Preoperative short-term radiation therapy (25 Gy, 2.5 Gy twice daily) for primary resectable rectal cancer (phase II). Br J Cancer. 2005;92:1209-14.

10. Bregendahl S, Emmertsen KJ, Lous J, Laurberg S. Bowel dysfunction after low anterior resection with and without neoadjuvant therapy for rectal cancer: a population-based cross-sectional study. Color Dis. 2013;15:1130-9.

11. Emmertsen KJ, Laurberg S. Low anterior resection syndrome score: development and validation of a symptom-based scoring system for bowel dysfunction after low anterior resection for rectal cancer. Ann Surg. 2012; 255:922-8.

12. Whistance RN, Conroy T, Chie W, Costantini A, Sezer O, Koller M, Johnson CD, Pilkington SA, Arraras J, Ben-Josef E, Pullyblank AM, Fayers P, Blazeby $J M$, European Organisation for the Research and Treatment of Cancer Quality of Life Group. Clinical and psychometric validation of the EORTC QLQ-CR29 questionnaire module to assess health-related quality of life in patients with colorectal cancer. Eur J Cancer. 2009;45:3017-26.

13. Ahmed KA, Correa CR, Dilling TJ, Rao NG, Shridhar R, Trotti AM, Wilder RB, Caudell JJ. Altered fractionation schedules in radiation treatment: a review. Semin Oncol. 2014;41:730-50.

14. Michalski JM, Gay H, Jackson A, Tucker SL, Deasy JO. Radiation dose-volume effects in radiation-induced rectal injury. Int J Radiat Oncol Biol Phys. 2010; 76:S123-9.

15. Roels S, Duthoy W, Haustermans K, Penninckx F, Vandecaveye V, Boterberg $T$, De Neve W. Definition and delineation of the clinical target volume for rectal cancer. Int J Radiat Oncol Biol Phys. 2006;65:1129-42.

16. Nijkamp J, Kusters M, Beets-Tan RG, Martijn H, Beets GL, van de Velde CJ, Marijnen CA. Three-dimensional analysis of recurrence patterns in rectal cancer: the cranial border in hypofractionated preoperative radiotherapy can be lowered. Int J Radiat Oncol Biol Phys. 2011:80:103-10.

17. Chen TY, Wiltink LM, Nout RA, Meershoek-Klein Kranenbarg E, Laurberg S, Marijnen CA, van de Velde CJ. Bowel function 14 years after preoperative short-course radiotherapy and total mesorectal excision for rectal cancer: report of a multicenter randomized trial. Clin Colorectal Cancer. 2015;14: 106-14.

18. Ansari N, Solomon MJ, Fisher RJ, Mackay J, Burmeister B, Ackland S, Heriot A, Joseph D, McLachlan SA, McClure B, Ngan SY. Acute adverse events and postoperative complications in a randomized trial of preoperative shortcourse radiotherapy versus long-course chemoradiotherapy for T3 adenocarcinoma of the rectum: Trans-Tasman Radiation Oncology Group Trial (TROG 01.04). Ann Surg. 2017;265:882-8.

19. Ciseł B, Pietrzak L, Michalski W, Wyrwicz L, Rutkowski A, Kosakowska E, Cencelewicz A, Spałek M, Polkowski W, Jankiewicz M, Styliński R, Bębenek M, Kapturkiewicz B, Maciejczyk A, Sadowski J, Zygulska J, Zegarski W, Jankowski M, Las-Jankowska M, Toczko Z, Żelazowska-Omiotek U, Kępka L, Socha J. Wasilewska-Tesluk E, Markiewicz W, Kładny J, Majewski A, Kapuściński W, Suwiński R, Bujko K, Polish Colorectal Study Group. Long-course preoperative chemoradiation vs. 5 × 5 Gy and consolidation chemotherapy for clinical T4 and fixed clinical T3 rectal cancer: Long-term results of the randomized Polish II study. Ann Oncol. 2019 Jun 13. https://doi.org/10.1093/ annonc/mdz186.

20. Erlandsson J, Holm T, Pettersson D, Berglund $\AA$, Cedermark B, Radu C, Johansson H, Machado M, Hjern F, Hallböök O, Syk I, Glimelius B, Martling A. Optimal fractionation of preoperative radiotherapy and timing to surgery for rectal cancer (Stockholm III): a multicentre, randomised, non-blinded, phase 3, non-inferiority trial. Lancet Oncol. 2017;18:336-46.

21. Couwenberg AM, Burbach JPM, Intven MPW, Consten ECJ, Schiphorst AHW, Smits AB, Wijffels NAT, Heikens JT, Koopman M, van Grevenstein WMU, Verkooijen HM. Health-related quality of life in rectal cancer patients undergoing neoadjuvant chemoradiation with delayed surgery versus shortcourse radiotherapy with immediate surgery: a propensity score-matched cohort study. Acta Oncol. 2019;58:407-16.

22. Downing A, Glaser AW, Finan PJ, Wright P, Thomas JD, Gilbert A, Corner J, Richards M, Morris EJA, Sebag-Montefiore D. Functional outcomes and health-related quality of life after curative treatment for rectal cancer: a population-level study in England. Int J Radiat Oncol Biol Phys. 2019;103: 1132-42. 
23. Chiloiro G, Boldrini L, Meldolesi E, Re A, Cellini F, Cusumano D, Corvari B, Mantini G, Balducci M, Valentini V, Gambacorta MA. MR-guided radiotherapy in rectal cancer: first clinical experience of an innovative technology. Clin Transl Radiat Oncol. 2019:18:80-6.

24. Jootun N, Sengupta S, Cunningham C, Charlton P, Betts M, Weaver A, Jacobs C, Hompes R, Muirhead R. Neo-adjuvant radiotherapy in rectal cancer - less is more? Color Dis. 2019 Sep 26. https://doi.org/10.1111/codi. 14863.

25. Valentini V, Marijnen C, Beets G, Bujko K, De Bari B, Cervantes A, Chiloiro G, Coco C, Gambacorta MA, Glynne-Jones R, Haustermans K, Meldolesi E, Peters F, Rödel C, Rutten H, van de Velde C, Aristei C. The 2017 Assisi Think Tank Meeting on rectal cancer: A positioning paper. Radiother Oncol. 2019 Aug 17. https://doi.org/10.1016/.jadonc.2019.07.001.

26. Fokas E, Allgäuer M, Polat B, Klautke G, Grabenbauer GG, Fietkau R, Kuhnt T, Staib L, Brunner T, Grosu AL, Schmiegel W, Jacobasch L, Weitz J, Folprecht G, Schlenska-Lange A, Flentje M, Germer CT, Grützmann R, Schwarzbach M, Paolucci V, Bechstein WO, Friede T, Ghadimi M, Hofheinz RD, Rödel C; German Rectal Cancer Study Group. Randomized phase II trial of chemoradiotherapy plus induction or consolidation chemotherapy as total neoadjuvant therapy for locally advanced rectal cancer: CAO/ARO/AIO-12. J Clin Oncol. 2019 May 31:JCO1900308. doi: https://doi.org/10.1200/JCO.19. 00308.

27. Gollins S, West N, Sebag-Montefiore D, Susnerwala S, Falk S, Brown N, Saunders M, Quirke P, Ray R, Parsons P, Griffiths G, Maughan T, Adams R, Hurt C. A prospective phase II study of pre-operative chemotherapy then short-course radiotherapy for high risk rectal cancer: COPERNICUS. Br J Cancer. 2018;119:697-706.

28. Rullier E, Rouanet $\mathrm{P}$, Tuech JJ, Valverde A, Lelong B, Rivoire M, Faucheron J L, Jafari M, Portier G, Meunier B, Sileznieff I, Prudhomme M, Marchal F, Pocard M, Pezet D, Rullier A, Vendrely V, Denost Q, Asselineau J, Doussau A. Organ preservation for rectal cancer (GRECCAR 2): a prospective, randomised, open-label, multicentre, phase 3 trial. Lancet. 2017;390:469-79.

29. Ogura A, Konishi T, Beets GL, Cunningham C, Garcia-Aguilar J, Iversen H, Toda S, Lee IK, Lee HX, Uehara K, Lee P, Putter H, van de Velde CJH, Rutten HJT, Tuynman JB, Kusters M; Lateral Node Study Consortium Lateral nodal features on restaging magnetic resonance imaging associated with lateral local recurrence in low rectal cancer after neoadjuvant chemoradiotherapy or radiotherapy JAMA Surg 2019 3:e192172. doi: https://doi.org/10.1001/ jamasurg.2019.2172.

30. Glynne-Jones R, Wyrwicz L, Tiret E, Brown G, Rödel C, Cervantes A, Arnold D. ESMO Guidelines Committee. Rectal cancer: ESMO Clinical Practice Guidelines for diagnosis, treatment and follow-up. Ann Oncol. 2017 Jul 1;28 (suppl_4).

\section{Publisher's Note}

Springer Nature remains neutral with regard to jurisdictional claims in published maps and institutional affiliations.

Ready to submit your research? Choose BMC and benefit from:

- fast, convenient online submission

- thorough peer review by experienced researchers in your field

- rapid publication on acceptance

- support for research data, including large and complex data types

- gold Open Access which fosters wider collaboration and increased citations

- maximum visibility for your research: over $100 \mathrm{M}$ website views per year

At $\mathrm{BMC}$, research is always in progress.

Learn more biomedcentral.com/submissions 